\title{
Comparison of calculation and simulation of evacuation in real buildings
}

\author{
Martin Szénay, Martin Lopušniak \\ Technical University of Košice, Slovakia \\ Faculty of Civil Engineering, Institute of Architectural Engineering \\ e-mail: martin.szenay@tuke.sk, martin.lopusniak@tuke.sk
}

\begin{abstract}
Each building must meet requirements for safe evacuation in order to prevent casualties. Therefore methods for evaluation of evacuation are used when designing buildings. In the paper, calculation methods were tested on three real buildings. The testing used methods of evacuation time calculation pursuant to Slovak standards and evacuation time calculation using the buildingExodus simulation software. If calculation methods have been suitably selected taking into account the nature of evacuation and at the same time if correct values of parameters were entered, we will be able to obtain almost identical times of evacuation in comparison with real results obtained from simulation. The difference can range from $1 \%$ to $27 \%$.
\end{abstract}

Key words: evacuation of building, evacuation time, calculation methods, input values, simulation

\section{Introduction}

There exist many methods and procedures how to determine time that is necessary for evacuation. When designing buildings, engineers use methods for the calculation of evacuation times. The methods must be verified, whether they provide results corresponding to the real situation. In the case of evacuation, this verification can be complicated in the practice. Different methods can be used for the determination of time and course of evacuation ranging from simple to complex ones. In the case of buildings with simple geometry, it is possible to use simplified calculation methods. So a question arises "at which degree are these simplified calculation methods reliable?" It is necessary to found boundaries, when simpler calculation methods can be used, and when the simulation is inevitable. One of them is possibility of using simulation software that will allow ascertaining any possible problems as early as when designing and solving the evacuation, and at the same time to bring the calculation closer to real results.

Analysis is focused on ascertainment of suitability of selected calculation methods. The comparison of calculation results when using different values of input parameters is integral part of analysis. Analyzed calculation methods were used for the determination of time of 
evacuation from three different buildings: shopping centre, community centre and apartment dwelling house.

\section{Description of analysed buildings}

The first building is the shopping centre (Fig. 1). This building has one floor, and 555 persons are present in accordance with the standard [1]. Several emergency escape routes are present in this building running to five emergency exits.

The second is the building of the community centre (Fig. 2). The building has 2 floors, and 79 persons are present in it according to the standard [1]. The building includes club premises and one staircase serving as the emergency escape route. The building has one emergency exit.

The last building is the apartment dwelling house (Fig. 3) with six floors, where 110 persons are present in apartments in accordance with the standard [1]. Individual floors are interconnected with one staircase forming one emergency escape route running to one emergency exit.

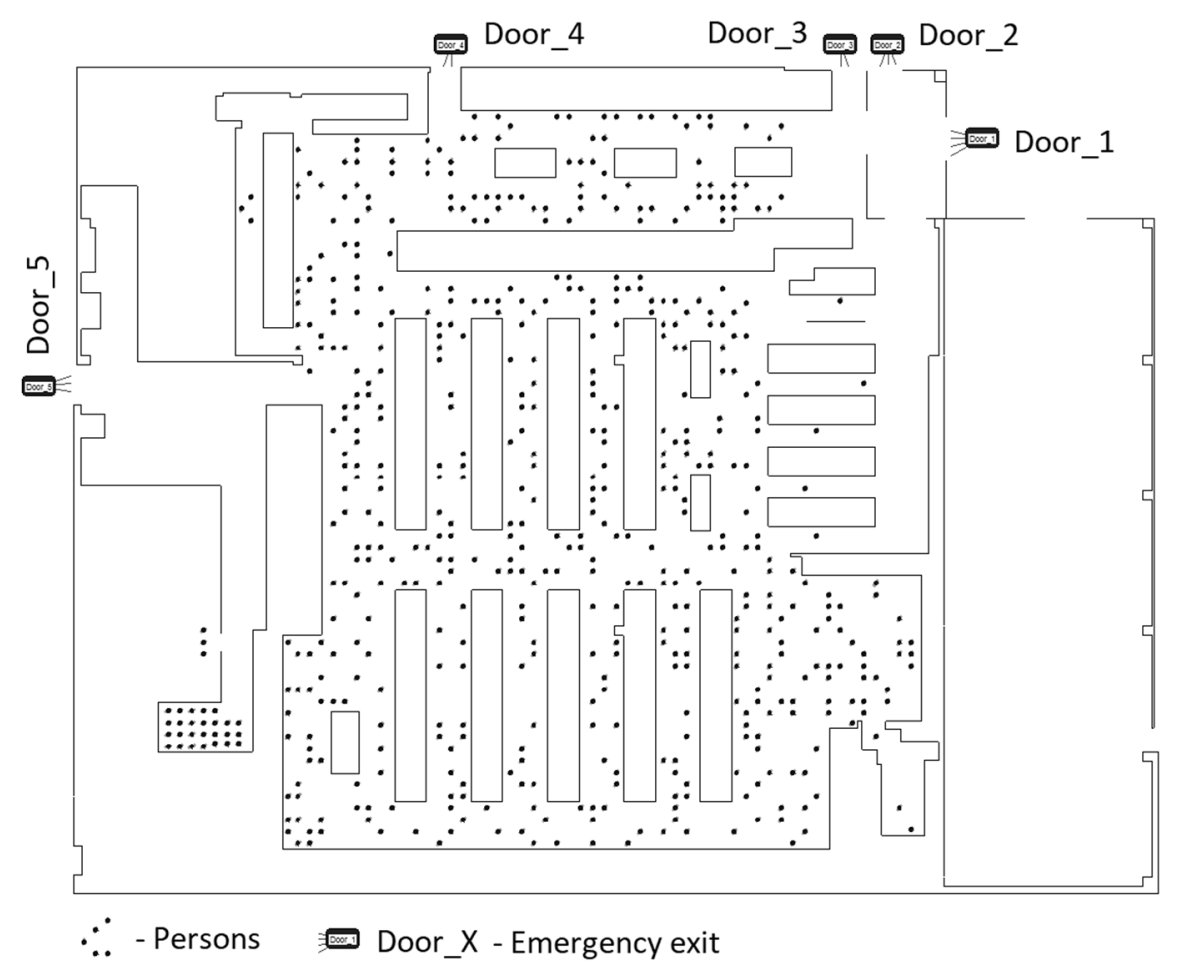

Figure 1: Geometry of shopping centre $-1^{\text {st }}$ floor 


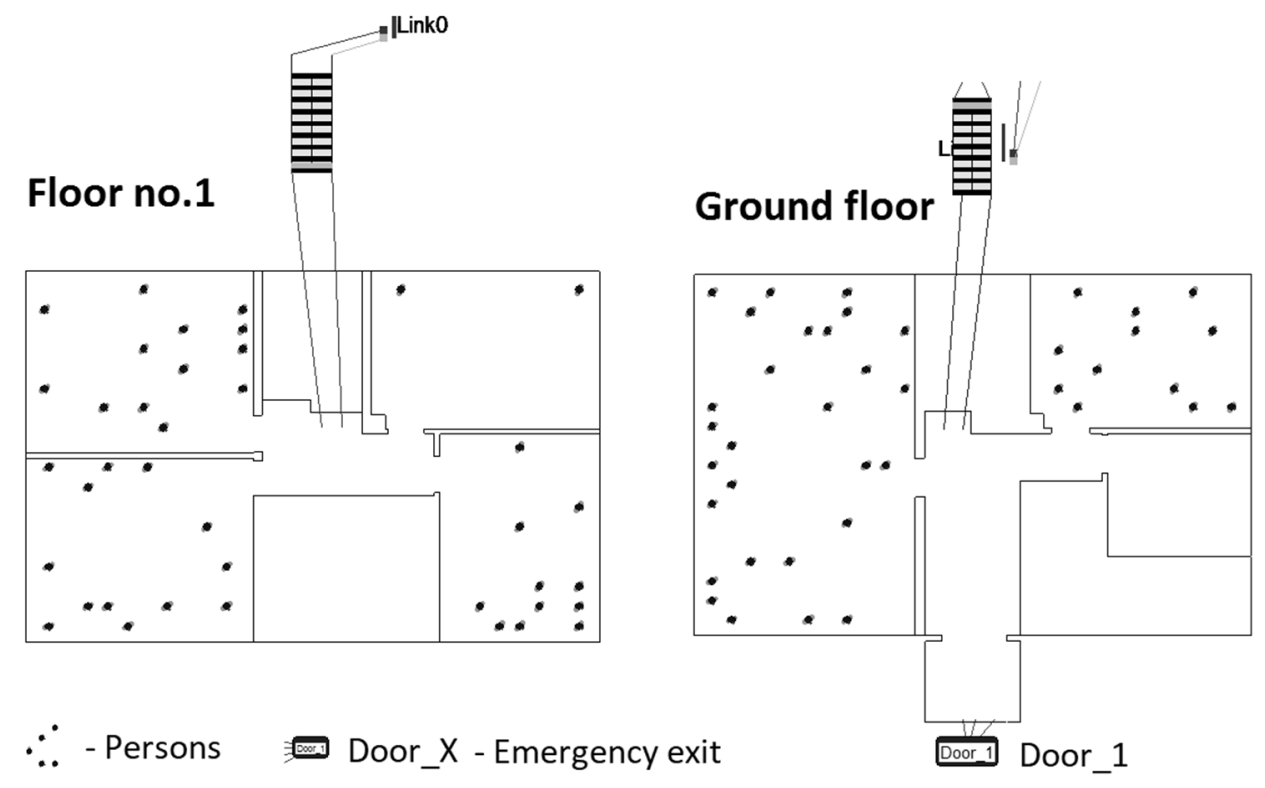

Figure 2: Geometry of community centre $-1^{\text {st }}$ and $2^{\text {nd }}$ floors

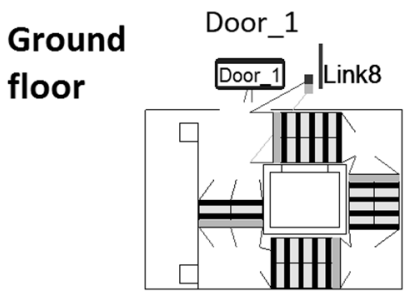

Floor no.2

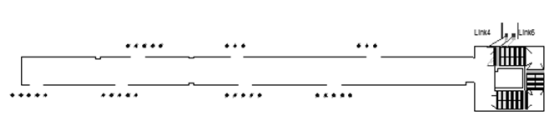

Floor no.4

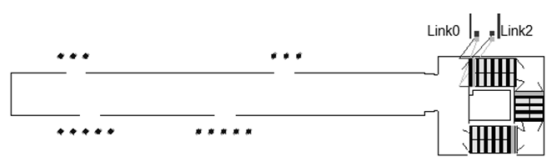

$\therefore$-Persons Door_X - Emergency exit
Floor no.1

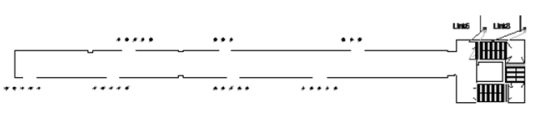

Floor no.3

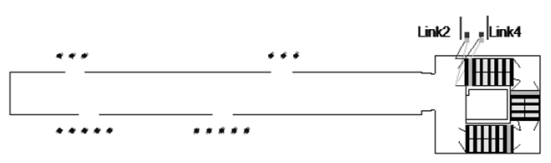

Floor no.5

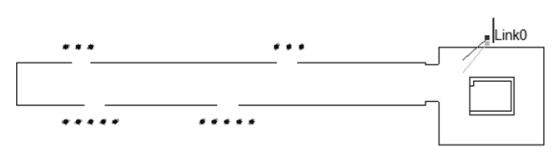

Figure 3: Geometry of apartment dwelling house 


\section{Program description}

BEXO is simulation software proposed in such a way to simulate evacuation of a large number of persons from big buildings. Both spatial and time proportions within BEXO are set by the two-dimension geometry of the building and by simulation clock. The spatial network is mapping geometry of the building, location of exits, internal sections, obstacles etc. The network consists of nodes and their connections. In BEXO, the node represents, as a standard, space with dimensions of $0.5 \times 0.5 \mathrm{~m}$, and in general, it has eight connections with adjacent nodes at $45^{\circ}$. Special properties can be assigned to nodes. For example nodes corresponding to stairs, obstacles or floor ground plan of space (some properties of the ground) will be categorised into three different classes. Virtual persons are important part of the program. Various psychical or physical characteristics (gender, age, aggressiveness and the like) can be assigned to these persons. The persons can walk from one node to another along interconnections of individual nodes. Trajectory of each individual person is monitored in the simulation, how he/she creates escape route from the building, or how he/she overcomes danger of fire such as heat and toxic gases $[2,3]$.

\section{Method}

Three methods of the calculation of evacuation time were used in the paper: numeric calculation in BEXO simulation software; simple calculation by parts and single calculation using one formula according to the standard [4].

Calculating the time of evacuation by part is more similar solution than calculating by one formula. The difference is that the escape route is divided into parts where the nature of the movement (plane, stairs) changes. Details of the calculation by parts but also of one formula are given by the Slovak standard [4].

In order these methods would be mutually comparable, equal input values of door capacity and speeds of movement of persons had to be used. Therefore capacities of doors (both interior and exit ones) were set at the simulation to such values that their widths would correspond to actual widths. More detailed calculation method by parts was used in single calculations for buildings No. 2 and 3. The calculation methods using a single formula was used for building No. 1. The following values were substituted in the case of simple calculations and simulations:

- Capacity of escape routes and doors $-K_{u}=1.21 \mathrm{p} \cdot \mathrm{m}^{-1} \cdot \mathrm{s}^{-1}$ (on flat ground) and 0.91 $\mathrm{p} \cdot \mathrm{m}^{-1} \cdot \mathrm{s}^{-1}$ (upstairs)

- Movement speed of persons $-v_{u}=0.5 \mathrm{~m} \cdot \mathrm{s}^{-1}$ (on flat ground) and $0,417 \mathrm{~m} \cdot \mathrm{s}^{-1}$ (upstairs)

- Width of escape routes according to geometry in meters

- Constant $-\mathrm{K}_{\mathrm{k}}=1$ and 0.75 or according to results obtained from simulation

- Length of escape route according to geometry obtained from results of simulation

- Capacity of escape routes and doors (British standard) $-K_{u}=1.33 \mathrm{p} \cdot \mathrm{m}^{-1} \cdot \mathrm{s}^{-1}$

- Movement speed of persons (British standard) $-\mathrm{v}_{\mathrm{u}}=1.2$ to $1.5 \mathrm{~m} \cdot \mathrm{s}^{-1}$ (on the ground) and $0.83 \mathrm{~m} \cdot \mathrm{s}^{-1}$ (upstairs)

The calculation of the time of evacuation did not include the smoke, and only persons without a handicap were considered. 
Models of buildings were created in the simulating software, and equal conditions were set for speed of people movement and door capacities. Simulations were implemented ten times (each simulation included different initial positions of persons), and results were averaged. Time of evacuation, maximum distance moved and constant were determined from results of simulation. These values were used for the calculation by parts or using one formula. Next, the simple calculation was carried out for one person. Models of building were modified in the simulation software, and movement speed of persons and capacities of doors were set according to values set in advance from British standards (each simulation included different initial positions of persons), and results were averaged.

Building No. 1 includes five scenarios of evacuation: 5 emergency exits from the building (Sc. 1.1; Sc. 1.2; Sc. 1.3 a Sc. 1.4). Emergency exit no. 3 (Door_3) did not use any person. Building No. 2 includes three scenarios of evacuation: whole building (Sc. 2.1), ground floor only (Sc. 2.2), first floor only (Sc. 2.3). Building No. 3 includes one scenario: vertical staircase as a protected escape route (Sc. 3.1).

\section{Results}

Table 1: Constant values obtained from simulation results

\begin{tabular}{|c|c|c|c|c|c|c|c|}
\hline \multicolumn{4}{|c|}{ Building No. 1 } & \multicolumn{3}{c|}{ Building No. 2 } & Building No. 3 \\
\hline Sc. 1.1 & Sc. 1.2 & Sc. 1.3 & Sc. 1.4 & Sc. 2.1 & Sc. 2.2 & Sc. 2.3 & Sc. 3.1 \\
\hline 0.54 & 0.60 & 0.73 & 0.60 & 0.62 & 0.75 & 0.83 & 0.59 \\
\hline
\end{tabular}

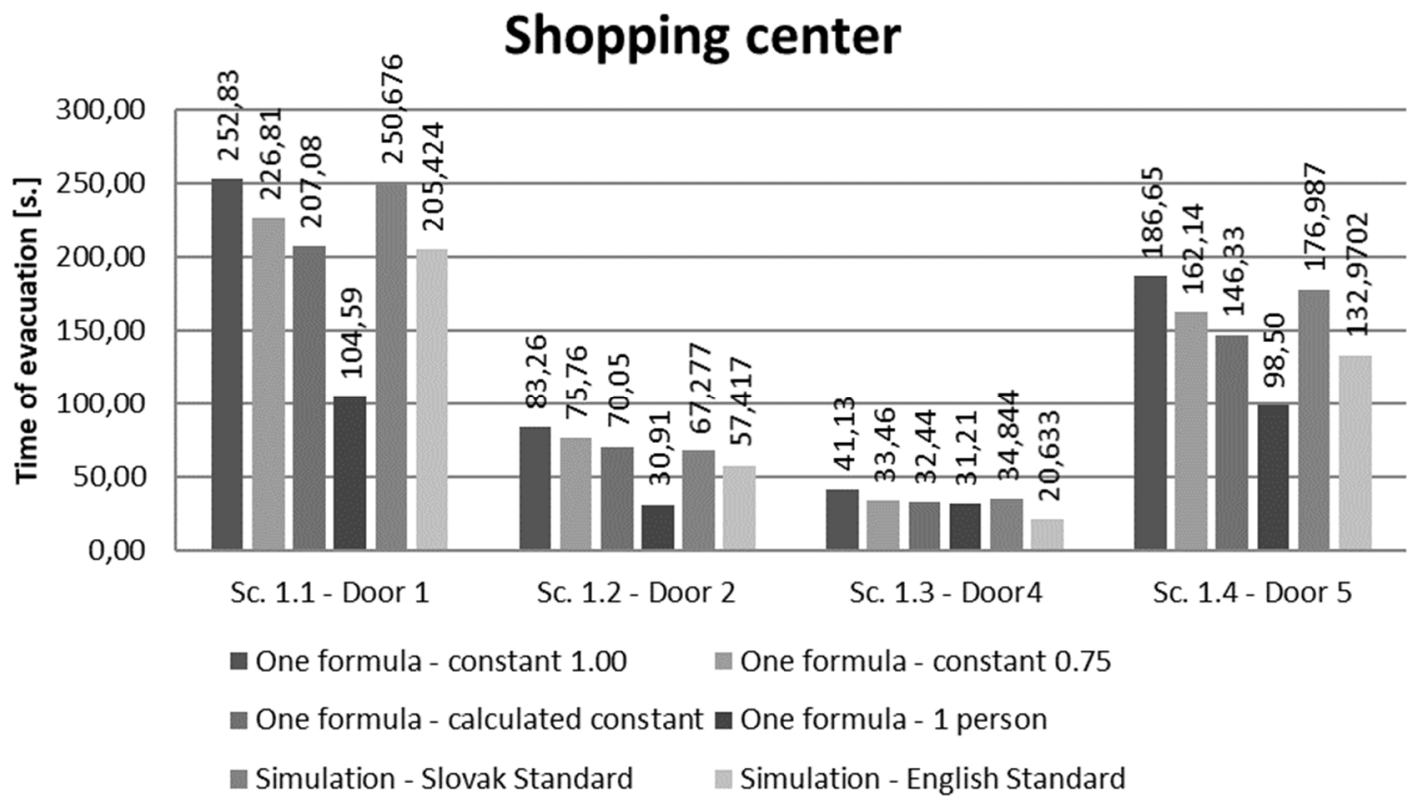

Figure 4: Results for building No. 1 - shopping centre 


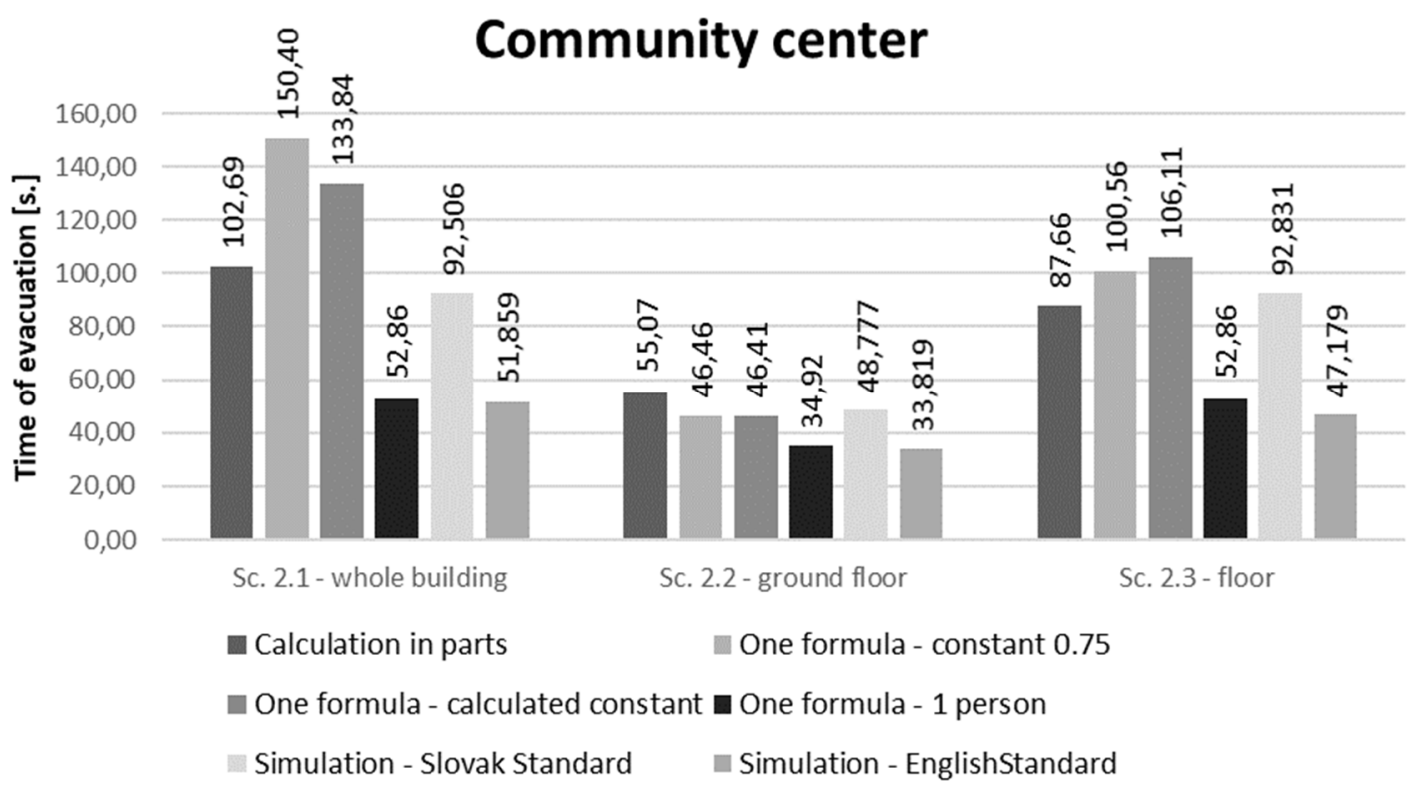

Figure 4: Results for building No. 2 - community centre

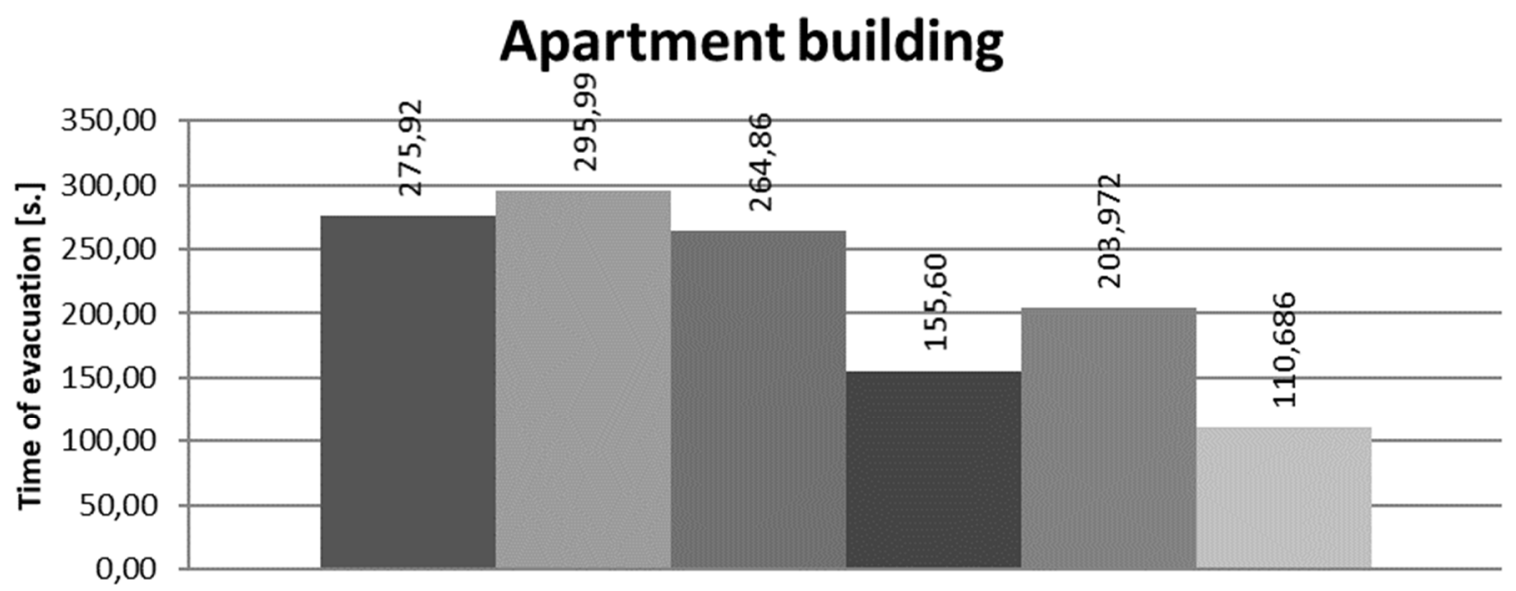

Sc. 3.1 - vertical staircase as a protected escape route

- Calculation in parts

- One formula - constant 0.75

- One formula - calculated constant $\mathbf{0}$ One formula - 1 person

= Simulation - Slovak Standard $\quad$ Simulation - EnglishStandard

Figure 6: Results for building No. 3 - apartment dwelling house 


\section{Discussion}

Buildings No. 2 and 3 have the vertical nature of evacuation with movement of persons mainly downstairs. The calculation using one formula and calculated constant demonstrated significantly higher time of evacuation than the calculation by parts or by simulation - the difference ranges from $22.99 \%$ to $43.26 \%$. In order to come near the simulation by results of the simple calculation, the calculation by parts can be considered the most suitable methods using accurate values of lengths of escape routes obtained from results of the simulation - the difference ranges from $4.88 \%$ to $27.17 \%$.

Building No. 1 has the horizontal nature of evacuation; persons are moved mainly on the plane. Results obtained for this building have demonstrated that when using constants 1 and 0.75 , the results do not draw nearer to the real time obtained from simulation. However, after the substitution of the correct constant into the calculation using one formula, time of horizontal evacuation can come near to real results obtained from simulation - difference is ranging from $0.91 \%$ to $5.51 \%$. At the same time, the calculation by parts is irrelevant in this case.

When comparing the resulting times of evacuation obtained from simulation with the Slovak and British input values, a difference up to $43.03 \%$ can be seen in favour of the British standards.

\section{Conclusion}

The paper was focused on suitability of the use of selected calculation methods.

- The time of vertical evacuation in the case of buildings with several floors should be calculated using the methods by parts, by which we will achieve the results drawing nearer to the results obtained from simulation. When using the calculation with one formula, the results are drawing apart from simulation.

- In the case of buildings with the horizontal nature of evacuation, it is more suitable to use the calculation with one formula, but the real value of constant must be taken into account (the average value from the longest and shortest distance moved by the evacuated person).

- It is suitable to consider revision of input values used in calculations because their results are greater by more than $35 \%$ in comparison with British input values.

\section{Acknowledgements}

This work was supported by grant project 2/0042/17 "Solar energy influences and integrated envelopes on the quality of the environment in buildings and cities."

This paper was created thanks to the financial support from the EU Structural Funds, through the R\&D Operational Program and project OPVaV-2008/2.2/01-SORO "Architectural, engineering, technological and economic aspects of the design of energy efficient buildings, codenamed ITMS: 26220220050; which is financed by EC funds.

\section{References}

[1] STN 92 0241: 2012: Požiarna bezpečnost' stavieb - Obsadenie stavieb osobami. 
[2] Building - EXODUS Tutorial

[3] The International Association for Fire Safety Science. [online, 29. 10. 2015]: <http://www.iafss.org/publications/fss/5/795/view>

[4] STN 92 0201-3: 2000: Požiarna bezpečnost' stavieb - Spoločné ustanovenia - Čast' 3: Únikové cesty a evakuácia. 